\title{
"Seja homem": a narrativa, seja homem, e sua influência na subjetividade masculina
}

DOI: https://doi.org/10.35168/2176-896X.UTP.Tuiuti.2020.Vol7.N62.pp98-120

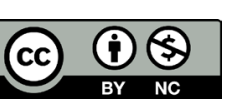

Thais Tatiane Stela Beal

Universidade Tuiuti do Paraná (UTP), Curitiba, PR, Brasil. Graduação em andamento em Psicologia. E-mail: thaisbeal24@gmail.com Orcid: https://orcid.org/0000-0002-6971-9983

Cláudia Silva Mário

Graduação em Direito - UniDomBosco. Email: claudia.smscwb@gmail.com Orcid: https://orcid.org/0000-0002-2078-6763 -

Sandra Cristine Machado Mosello Universidade Tuiuti do Paraná (UTP), Curitiba, PR, Brasil. Mestre em Psicologia Social Comunitária pela Universidade Tuiuti do Paraná (UTP). E-mail: scmpsico@gmail.com Orcid: https://orcid.org/0000-0002-8212-567X

Juliane Pereira Vieira Universidade Tuiuti do Paraná (UTP), Curitiba, PR, Brasil. Graduanda em Psicologia pela Universidade Tuiuti do Paraná (UTP). E-mail: juliane.pereira.18@hotmail.com Orcid: https://orcid.org/0000-0003-2170-5694 -

Rosilene Monteiro da Silva

Graduação em Administração pelo Centro Universitário Internacional, UNINTER, Brasil E-mail: rosilenefinasa@hotmail.com Orcid: https://orcid.org/0000-0002-2050-0526

Revista Tuiuti: Ciência e Cultura, v.7 n.62. p. 98-120, Curitiba, 2021 


\section{"Seja homem": a narrativa, seja homem, e sua influência na subjetividade masculina}

\section{Resumo}

Os discursos sobre as subjetividades relacionadas ao gênero são recorrentes na sociedade e na esfera acadêmica. Sendo impossível abarcar o todo, esta pesquisa trabalhou com um recorte de realidade. Neste momento nos debruçamos sobre o universo masculino, com o objetivo geral de compreender como a narrativa, "seja homem", sendo uma frase tão popularizada em diferentes meios sociais, pode produzir efeitos na subjetividade masculina. Após a análise das coletas de dados sobre um olhar psicanalítico, as falas dos entrevistados fizeram emergir algumas categorias que nortearam a análise dos conteúdos, sendo elas: Inscrição Cultural, Ser Homem, Representação Fálica, Representação do Feminino, Divisão de Tarefas e Sexualidade. O estudo permitiu verificar, que mesmo em 2020, ainda encontramos indícios do machismo estrutural, hoje também reconhecido como algo prejudicial ao próprio homem, que se constituiu pela masculinidade tóxica. Ouvir sobre o peso que a narrativa "seja homem" e os seus desdobramentos, afeta a cada um, nos possibilitou a reflexão sobre essa condição do ser homem em nossa cultura. Conclui-se que mesmo sendo um assunto que vem ganhando espaço e corpo nas discussões em diferentes áreas do conhecimento, percebe-se ainda que muitas vezes surge a partir de uma reivindicação feminina, que busca equidade. Existe vontade de mudança, a busca por um novo padrão de masculinidade emerge a cada conversa e a cada discussão possibilitada na sociedade, visto que muitos homens se sentem convocados a avaliar o que escutam sobre como poderiam ser, e sentem-se impulsionados a mudanças.

Palavras-chave: Subjetividade Masculina. Representações. Gênero. Identidade. 


\section{"Be a man": narrative, be a man, and its influence on male sobjectivity}

\section{Abstract}

Discourses on gender-related subjectivities are recurrent in society and in academia. Since it is impossible to cover the whole, this research has worked with a reality cutout. At this moment we focus on the male universe, with the general objective of understanding how the narrative, "be a man", being a phrase so popularized in different social environments, can produce effects on male subjectivity. After the analysis of the data collection on a psychoanalytical view, the lines of respondents emerged some categories that guided the analysis of content: Cultural Inscription, Being a Man, Phallic Representation, Feminine Representation, Division of Tasks and Sexuality. The study showed that even in 2020, we still found evidence of structural machismo, now also recognized as something harmful to men themselves, which was constituted by toxic masculinity. Listening to the weight that the narrative "be man" and its unfoldings, affects each one, has allowed us to reflect on this condition of being man in our culture. We conclude that even though it is a subject that has been gaining space and body in the discussions in different areas of knowledge, it is still perceived that many times it arises from a feminine claim that seeks equity. There is a will to change, the search for a new pattern of masculinity emerges at every conversation and at every discussion made possible in society, since many men feel called to evaluate what they hear about how they could be and feel driven to change.

Keywords: Male subjectivity. Representations. Gender. Identity. 


\section{"Seja homem": a narrativa, seja homem, e sua influência na subjetividade masculina}

\section{Introdução}

Tanto no espaço acadêmico quanto na sociedade proliferam as discussões sobre as subjetividades relacionadas ao gênero. Questões sobre o desenvolvimento subjetivo de cada gênero, sobre a divisão do trabalho entre gêneros e sobre os papeis sociais esperados para cada gênero são apenas algumas das possibilidades de abordar este tema. Uma vez que o gênero se refere "ao modo como as diferenças sexuais são compreendidas numa dada sociedade, num determinado grupo, e em determinado contexto" Louro (1997, p. 77) aduz. Pensar sobre o conceito de gênero é pensar enquanto um conceito que perpassa por construções históricas e culturais que variam de acordo com cada época e meio social, e que geram expectativas, bem como determinam comportamentos e normas sobre a condutas dos indivíduos, baseadas unicamente na diferença sexual anatômica.

Dito de outro modo, como são expectativas, não representam construções individuais, mas uma espécie de imposição social, que pode não corresponder aquilo que o sujeito espera de si mesmo (Nader \& Caminoti, 2014).

Segundo Scott (1995) o termo "gênero" torna-se uma forma de indicar "construções culturais" - a criação inteiramente social de ideias sobre os papéis adequados aos homens e às mulheres. Trata-se de uma forma de se referir às origens exclusivamente sociais das identidades subjetivas de homens e de mulheres. "Gênero" é, segundo esta definição, uma categoria social imposta sobre um corpo sexuado.

Segundo Bourdieu (1995), a divisão do mundo foi fundada sobre as diferenças biológicas, aquelas que se referem à divisão sexual do trabalho, da procriação e da reprodução e opera como a mais fundada das ilusões coletivas estabelecidas como um conjunto objetivo de referências. As representações de gênero estruturam a percepção e a organização concreta e simbólica de toda a vida social. Normatiza papeis que os sujeitos devem seguir. Diversos estudos apontam para a existência do machismo estrutural no Brasil. 


\section{"Seja homem": a narrativa, seja homem, e sua influência na subjetividade masculina}

O Brasil, se modelou na estrutura patriarcal, no domínio dos homens, no gênero masculino, seja em atividades econômicas ou sociais. À mulher coube um espaço limitado a vida doméstica e por muito tempo foi vista como propriedade, do pai e posteriormente do marido, sendo parte do lar, uma mulher do lar. Essas construções vêm se remodelando com o passar dos anos, mas o patriarcado ainda tem grande influência dentro da sociedade e das relações. O poder patriarcal é uma das raízes do machismo estrutural, dá origem aos ideais de como ser homem e ser mulher dentro de uma sociedade, "dividindo papéis em razão do gênero e dando um tratamento desigual para as pessoas" (Oliveira, Oliveira \& Cardoso, 2020, p. 95)

Tendo consciência deste fato, não cabem discussões sobre a concordância ou não da existência do machismo estrutural, mas sim, apontam a necessidade de questionamentos, sobre como o machismo estrutural habita em cada um de nós, sendo sujeitos abrigados por esta realidade.

Para os homens referente imposição, contém muito sobre a masculinidade tóxica ou hegemônica que Schreiner (2008) define como sendo uma forma de configuração da sociedade que aceita o problema do patriarcado e que entende a posição do homem como dominante e a mulher como subordinada. Diferentes estudos realizados nos últimos anos a respeito da construção da subjetividade masculina, certificam alguns dos problemas enfrentados pelo homem contemporâneo diante da masculinidade tóxica.

Silva e Macedo (2012) discorrem sobre "O que é ser homem hoje em dia?”. O estudo aponta a necessidade de se rever as habituais funções masculinas, como a de único provedor, figura de autoridade e pequena participação no cuidado com os filhos e com a casa. Outro estudo denominado, "O Silêncio dos Homens", lançado em agosto de 2019, realizado com mais de 20.000 pessoas, possibilitou a escuta de temas que eram percebidos em rodas de conversa do cotidiano social e identificou na prática os problemas enfrentados por homens nos dias de hoje. Segundo o estudo: 7 a cada 10 homens não falam sobre seus medos e dúvidas com amigos, e esse silêncio pode 


\section{"Seja homem": a narrativa, seja homem, e sua influência na subjetividade masculina}

ser a causa de muitos problemas, como a violência doméstica, assédio, as altas taxas de suicídio por parte de homens e diversas outras questões que podem ser desencadeadas. Além do estudo realizado sobre o tema, também nos deparamos com vários projetos sociais sobre essa temática.

O projeto "Okara" criado em 2017, foi outro projeto que abordou a mesma temática, tendo como objetivo ajudar jovens rapazes a resgatar valores que muitas vezes são esquecidos, como compaixão, respeito e responsabilidade, além de repensar essa masculinidade na qual são obrigados, mesmo que inconscientemente, a viver (Basilio, 2019).

Ainda em 2017, o Projeto "Pai: os desafios da paternidade atual", traz um espaço de escuta, onde experiências, desafios, vivencias e dificuldades são discutidos abertamente. Com um olhar voltado em como esses homens tem exercido essa paternidade e não no intuito de apontar falhas ou exaltar exemplos, mas sim pelo olhar responsável para esse caminho de transformação, experienciando um momento repleto de novos significados, transformações e responsabilidades, tecendo um movimento de reavaliação dos valores e da criação tida pelos seus próprios pais (Gabriel \& Dias, 2011).

O movimento MEMOH é um espaço acolhedor para homens. São promovidas rodas de conversas onde são debatidos temas sobre masculinidade, com o objetivo de promover uma equidade de gênero, trazendo uma reflexão sobre o modo de agir do homem para consigo, com o outro e com a sociedade (Memoh, 2020).

Diante deste cenário social, que produz e replica imposições aos gêneros, encontramos uma imensa possibilidade de trabalho. A própria linguagem cotidiana abriga em seu bojo, frases pronunciadas cotidianamente que podem influenciar as subjetividades de gênero, tanto para mulheres quanto para homens. Sendo impossível abarcar o todo, esta pesquisa trabalhou com um recorte de realidade. Neste momento nos debruçamos sobre o universo masculino, com o objetivo geral de compreender como a narrativa, "seja homem", uma frase tão popularizada em diferentes meios sociais, pode produzir efeitos na subjetividade masculina. Especificadamente buscamos identificar 


\section{"Seja homem": a narrativa, seja homem, e sua influência na subjetividade masculina}

o impacto da narrativa, seja homem, na escuta masculina, reconhecer os possíveis significados da afirmativa, seja homem, na fala masculina e feminina e verificar o impacto dessa afirmativa, em quem pronuncia e em quem escuta.

\section{Método}

Esta pesquisa teve caráter qualitativo. A pesquisa qualitativa proporciona um exame evidenciado de mundo, buscando compreender eventos em termos dos significados que as pessoas a eles concedem. Vieira e Zouain (2005) apontam que a pesquisa qualitativa atribui importância fundamental aos testemunhos dos sujeitos sociais implicados, aos argumentos e aos significados transmitidos por eles.

A pesquisa qualitativa tem se mostrado bastante eficiente no estudo de pequenas variantes da vida humana e na análise dos processos sociais ao longo do tempo (Mosello, 2018). Sua validade é acolhida em contextos nos quais se faz necessário captar aspectos psicológicos e a complexidade que abarcam para alguns temas determinados, sejam: estímulos, posicionamentos, perspectivas e convicções (Richardson, 1999).

A amostra deste estudo, foi composta por 24 pessoas, sendo 11 mulheres e 13 homens, na faixa etária entre 18 e 60 anos de idade, residentes no estado do Paraná e São Paulo. O método para a coleta de dados foi a entrevista. A entrevista é um processo de mediação para obter informação, um processo dialógico no qual o pesquisador e pesquisando interagem como autores criadores. $\mathrm{O}$ autor criador é quem dá forma ao conteúdo: ele não apenas registra passivamente os eventos da vida, mas recorta-os e os reorganiza esteticamente (Brait, 2005).

Dentro das possibilidades existentes de entrevista, optamos pela entrevista episódica. A entrevista episódica permite uma aproximação com o tema do estudo através de uma forma narrativa que possibilita descrever as experiências associadas ao contexto. Sendo assim, ela parte 


\section{"Seja homem": a narrativa, seja homem, e sua influência na subjetividade masculina}

de situações ou episódios vivenciados pelo entrevistado que sejam relevantes ao tema da pesquisa, numa combinação de narrativas orientadas para desvendar o conhecimento conceitual (Flick, 2009).

Devido a Pandemia COVID-19 e ao isolamento social, as entrevistas foram realizadas tanto na modalidade presencial quanto na modalidade remota, por meio de plataformas digitais. Os dados, as falas e os conteúdos foram analisados a partir da análise de conteúdo Laurence Bardin (2011).

\section{Procedimentos}

Após a aprovação do Projeto de Pesquisa pelo Comitê de Ética em Pesquisa da Universidade Tuiuti do Paraná, sob o protocolo de número CAAE 29642820.1.0000.8040, os convidados já selecionados através da rede de contato das alunas pesquisadoras foram contatados para participarem das entrevistas episódicas. A cada contato pessoal foram esclarecidos os objetivos e procedimentos de investigação e com o aceite em participar, as entrevistas foram marcadas de acordo com a disponibilidade e facilidade de acesso às plataformas digitais ou pessoalmente, sendo respeitadas todas as recomendações da OMS e Ministério da Saúde quanto ao distanciamento social. Todos os participantes assinaram o Termo de Consentimento Livre e Esclarecido, e participaram individualmente de uma entrevista episódica semiestruturada com questões abertas. As entrevistas foram gravadas em áudio, devidamente autorizada pelos participantes, e posteriormente transcritas. A técnica de Análise de Conteúdo desenvolvida por Bardin (2011) foi utilizada para a identificação de conteúdo, codificados em categorias de respostas.

\section{Análise dos dados}

A coleta de dados fez emergir das falas dos entrevistados algumas categorias que nortearam a análise dos conteúdos. Durante as entrevistas individuais foi possível perceber o surgimento de 


\title{
"Seja homem": a narrativa, seja homem, e sua influência na subjetividade masculina
}

algumas narrativas recorrentes em torno da construção de uma posição pessoal, perpassada pelo discurso sociocultural. Com base nas entrevistas, foi possível identificar as influências culturais na formação da identificação com a masculinidade e com feminilidade dos sujeitos entrevistados, surgindo assim a categorização "Inscrição Cultural”.

No nascimento cada sujeito já receberá diversos signos de atribuição de gênero derivados simplesmente pela atribuição sexual, indo das características anatômicas para designação de atributos socioculturais. Dessa forma, segundo (Connel \& Messerchmidt, 2013) o meio social condiciona o indivíduo a desempenhar papéis hegemônicos. Em diversas falas da amostra deste estudo, foi possível verificar conceitos e opiniões como: que meninos são fortes, não podem chorar, brincam com "carrinhos", espadas, "armas", "meninos vestem azul”, e que além disso, não precisam realizar tarefas domésticas. E que as "meninas vestem cor de rosa” e ajudam com as tarefas de casa. Na vida adulta não é diferente, a mulher é considerada o sexo frágil, romântica, dona de casa e responsável por cuidar dos filhos. Por outro lado, o homem é visto como o provedor da família, forte, viril e detentor de elevada robustez emocional. Tais conceitos emergiram durante as entrevistas, tanto na fala dos homens entrevistados, como das mulheres:

\begin{abstract}
Quando criança a gente separa o que um menino ou uma menina deve fazer, às vezes numa brincadeira, até na hora de comprar um brinquedo, as coisinhas de cozinha é da menina e do carrinho do menino até mesmo da criação; Já é uma cultura que vem azul é de menino, rosa é de menina; Aprendi na família que homem tinha que sair trabalhar e mulher ficar dentro de casa, cuidando da família; Homem trabalha e mulher faz o serviço em casa e cuida dos filhos; Hoje em dia a visão é que o homem é o provedor e a mulher é o sexo frágil.
\end{abstract}

Almeida (1996, p.2) define que "masculinidade não é apenas a formulação cultural de um dado natural. Ela é um processo de construção social contínuo, frágil e disputado. A manutenção desse 


\section{"Seja homem": a narrativa, seja homem, e sua influência na subjetividade masculina}

processo é permanentemente vigiada e, sobretudo, autovigiado. O homem é socialmente cobrado e deve, o tempo todo, evitar posturas não másculas e também fornecer provas de sua masculinidade". Já segundo Beauvoir (1967, p.9) "ninguém nasce mulher: torna-se mulher". Nenhum destino biológico, psíquico, econômico define a forma que a fêmea humana assume no seio da sociedade; é o conjunto da civilização que elabora esse produto intermediário entre o macho e o castrado que qualificam ou desqualificam, como - feminino."

A narrativa "Ser homem" emergiu como uma forte categoria deste estudo. Categoria subsidiada por uma descrição dos entrevistados sobre a própria percepção no que tange a posição masculina diante da sociedade e da própria subjetividade, ao se depararem com a demanda ou imposição sobre si mesmos, diante da busca por ocupar esta posição social e discursiva, "ser homem".

Foi possível perceber como a busca por esta identidade masculina gera representações deste lugar ao possuidor deste gênero, fato diretamente justificado e correlacionado ao corpo biológico, na maioria das vezes através de falas de ditos familiares e sociais, que vinculam o masculino, ou seja, àquele possuidor de um pênis, e o validam como sujeitos possuidores de força, coragem, integridade, chefes de família, dotados da capacidade de superação das adversidades e de controle das emoções através da capacidade racional. Tais dados durante as entrevistas, emergiram nas falas das mulheres do seguinte modo:

uso essa expressão principalmente com o meu filho, em alguns momentos, as vezes que ele está chorando demais, aí eu falo - pare! que homem não fica chorando desse jeito; ser homem é um ser humano, que seja capaz de ser forte, corajoso; ser homem é ter força, coragem, ação e objetivo; $\mathrm{O}$ homem deveria ser trabalhador e de bom caráter; mas a imagem do homem sempre é aquela imagem de muita força.

Bem como na fala dos homens entrevistados: 


\title{
"Seja homem": a narrativa, seja homem, e sua influência na subjetividade masculina
}

\begin{abstract}
Seja homem, engole esse choro, ser homem não é você se enfraquecer diante de uma situação supérflua e sim você trazer sustento para dentro da sua casa.; ser homem é ser chefe de família, tanto quanto chefe de família do lar perante a sua esposa; me diziam que eu tinha que ser homem, que eu tinha que me sustentar e não podia chorar; o homem não chora, o homem não lava louça, que o homem tem que se sustentar e eu aprendi a ser assim; À sociedade meio que implanta em você essa figura de não ter medo, ser mais firme, mais responsabilidade, que não quebra com facilidade, uma figura mais superior digamos; $\mathrm{O}$ homem essa persona forte o cara que tem que dar segurança que tem que prover; mas a imagem do homem sempre é aquela imagem de muita força.
\end{abstract}

As categorias acima certificam o quanto a família tem um papel central no processo de formação do sujeito, e de transmissão da cultura, pois é a estrutura fundante que carrega sentido e conteúdo na composição do eu de seus integrantes.

Barbosa (2013) afirma que os parâmetros usados na definição de masculinidade e virilidade geralmente se apoiam na diferenciação binária, entre papéis masculinos e femininos, na distinção biológica, no discurso do corpo, na divisão de trabalho, na estrutura de poder, na dominação da esfera pública e na necessidade de controlar emoções e sentimentos. Oportuno incluir a formação da identidade, que assim como a diferença são processos de produção simbólica e discursiva, atreladas as relações de poder, o que garante certos privilégios, demarca fronteiras, incluem e excluem (Barbosa, 2014). Portanto, essa diferenciação binária sempre carregará um termo mais privilegiado, além de normalizar e fixar uma identidade como regra, que adquire características positivas, tornando-se parâmetro para outras identidades e se fixando "natural, desejável e única" (Silva, 2013, como citado em Barbosa, 2014).

Boris (2000) discorre sobre a construção da subjetividade e da condição masculina que é, ao mesmo tempo, um complexo processo sociocultural de identificação com um modelo internalizado de masculinidade, previamente institucionalizado e frequentemente rígido. Boris (2000) afirma que assim, 


\section{"Seja homem": a narrativa, seja homem, e sua influência na subjetividade masculina}

os meninos aprendem desde cedo e antes de quase tudo, quais são as atitudes consideradas socialmente inadequadas a um homem, para, só então, incorporar as devidas posturas sociais “de homem”.

Freud (1914/2009) em seu texto, sobre o Narcisismo diz que a identificação tem um papel fundamental na escolha de objeto por apoio, em que o indivíduo se constitui como tal baseando-se no modelo parental ou substituto. De acordo com Roudinesco e Plon, (1998, p. 365) "a identificação é processo central pelo qual o sujeito se constitui e se transforma, assimilando ou se apropriando, em momentos chave de sua evolução, dos aspectos, atributos ou traços dos seres humanos que o cercam”.

A identificação sem o investimento sexual seria resultado da "capacidade ou vontade de colocarse numa situação idêntica” (Freud, 1921/2009, p. 117) do outro. Podendo ser gerada através da identificação, em específico, relacionada a comunidade, a vida social e que, posteriormente, o vínculo presente na sociabilidade, que se coloca como ideal do eu para cada membro da comunidade.

De acordo com Freud (1921/2009) ainda é difícil descolar masculinidade e feminilidade do sexo anatômico, pois os atributos que são representativos de cada sexo são próprios da cultura. Ao homem é proposto amplificar seus talentos e aptidões, já a mulher é direcionada a controlar seus arrojos e ser conduzida, colocando o masculino em uma posição de dominação pelo poder, ou seja, uma dominação fálica. Esse pensamento corrobora com a próxima categoria que emergiu nas falas da amostra que foi a "Representação fálica", descrita através da percepção dos entrevistados sobre a virilidade e a força, ou seja, da masculinidade enquanto um lugar que não demonstra fraquezas ou fragilidade, que possui um lugar de protagonismo. Sempre pronto e disposto, características entendidas como atributos masculinos. As seguintes falas justificaram esta categoria:

Pra mim “ser homem” é ter pinto; ter hombridade, não só se manter seguro, forte, mas sim ser alguém verdadeiro, de palavra; o homem pode ser um pouco mais forte, mas querendo ou não, o porte físico é tudo; os filmes, antes eram muito masculinos, 


\title{
"Seja homem": a narrativa, seja homem, e sua influência na subjetividade masculina
}

\begin{abstract}
né, tinha tiro ,vamos dizer... o filme do Rambo, o cara é fodão é o forte, vai lá, dá tiro, mata, faz e acontece e não sente nada; eu sou o superior, é melhor do que mulher; homem é a pessoa mais forte da relação; ser homem pra mim está relacionado a ser forte; ser homem pra mim está baseado em como a própria sociedade vê, está muito relacionado a ser forte; acho que homem não deve apresentar vulnerabilidade; no fundo no fundo a sociedade gosta de ver homens no comando, em posição de destaque; o homem ainda é considerado superior, mais forte, capaz e inteligente.
\end{abstract}

Diferentes estudos sobre o tema, conceituam os resultados encontrados nas falas que evidenciaram esta categoria. Silva e Macedo (2012) discorrem que o homem necessita, simbolicamente, ter incorporado o falo, pois representa a posse de todos os seus atributos masculinos, como ser o protagonista e viril em todos os âmbitos. Silva (2006), em seu estudo sobre a "Masculinidade na história: a construção cultural da diferença entre os sexos" afirma que alguns homens da era vitoriana, costumavam se descrever através da forma de se vestir, a forma de andar, a maneira de se comportar, a entonação de voz. Também era ressaltado a forma física, a musculatura, os contornos do corpo masculino, a elegância, o vigor físico e a beleza, e por fim, as qualidades psicológicas do homem, como a agilidade, a coragem, a distinção, a bravura, o heroísmo. Podemos perceber na atualidade que as referidas características sobre atributos identificados como masculinos, ainda correspondem ao vocabulário masculino atual.

Silva (2006, p. 121) ainda afirma que "a masculinidade hegemônica é uma configuração de gênero que incorpora a resposta atual aceita para o problema da legitimidade do patriarcado, garantindo a posição dominante dos homens e a subordinação das mulheres", ou seja, ainda existe um padrão cultural e o poder fálico é mantido pelos homens até a atualidade.

Mas, este lugar de posição fálica que subordina a mulher, ou seja, o feminino à uma posição inversa, uma posição de fragilidade e dependência, corresponde ao lugar que a mulher inscreve em si, em sua subjetividade na atualidade. 


\section{"Seja homem": a narrativa, seja homem, e sua influência na subjetividade masculina}

Quando entrevistamos as mulheres, surgiu uma possibilidade de impacto psicológico nas relações. Se os homens ainda mantem um discurso vitoriano, muitas mulheres mudaram suas falas e posicionamentos. Surge assim a categoria "Representação do Feminino", que durante as entrevistas foi marcada por falas de independência, reflexo das mudanças ocorridas nas famílias, na alteridade de papeis e da condição feminina que se apresentam na atualidade:

As mulheres tem muitas conquistas, pelo menos eu penso assim, estão na força de trabalho, são chefes de família; a mulher tem demonstrado ser cada vez mais ser forte, corajosa e capaz; minha mãe sempre conversou isso comigo: para eu nunca depender de ninguém, estude... nunca dependa de marido, pra gente trabalhar, que depender do marido é horrivel.

Somente uma dentre as onze entrevistadas, remeteu a feminilidade a maternidade. (...) "mulher fica mais com a parte de ser mãe do cuidado e do emocional".

As mudanças ocorridas no universo feminino ao longo das últimas décadas trouxeram novos atributos à mulher e possibilidades de mais liberdade e autonomia, até então as mulheres ficavam a mercê e eram subsidiadas pelo desejo impostos a elas pelos pais, marido e sociedade.

De acordo com Coelho (2002) muitas mudanças ocorridas se deram pela amplificação da força de trabalho feminina, através das mulheres que saíram em busca de emprego tendo como maior motivo às dificuldades financeiras. A mudança de atributos do universo feminino, não passa sem reflexos ao universo masculino. Assim, neste cenário atual constata-se que o homem está atravessando uma "crise da masculinidade".

Se, por muito tempo, a masculinidade era caracterizada por poder, força e virilidade, hoje em dia são diversas as definições que se cruzam para dar conta do que é ser homem. Conforme Silva (2006), as mudanças provocadas pelo feminismo desestabilizaram o modelo masculino tradicional 


\section{"Seja homem": a narrativa, seja homem, e sua influência na subjetividade masculina}

e impuseram a necessidade de sua revisão. Os impactos e as tensões entre os padrões tradicionais da identidade masculina foram sentidos com as mudanças ocorridas nas relações amorosas, sexuais, sociais e no trabalho. Discussões em torno de uma nova definição da identidade masculina e a possibilidade de se viver novas formas de ser homem na cultura ocidental gerou o que se pode chamar da "crise de masculinidade".

Atualmente o próprio conceito de papéis de gênero sofreu uma modificação dando lugar ao conceito de atributos, pois enquanto o gênero está calcado na construção de uma identidade masculina ou feminina, que delimita de forma rígida as atuações sociais e inter-relações entre os gêneros, os atributos possibilitam mais flexibilidade, ou seja, o sujeito mesmo na atuação do que é entendido e subjetivado como masculino ou feminino, pode desenvolver ou trazer consigo atributos que sejam imputados ao outro gênero.

Portanto, os atributos que são designados aos gêneros masculino e feminino são construções sociais que variam de acordo com cada cultura e tempo histórico, transformando os sujeitos em "intérpretes" e repetidores de comportamentos praticados no meio em que estão inseridos.

Mas, se até então, os gêneros exerciam papeis rígidos e atribuídos culturalmente, onde as atribuições das tarefas diárias da casa costumam representar um imperativo cultural, que muitas vezes gera insatisfação feminina pela falta de iniciativa da parte masculina, como fica o surgimento da possibilidade de exercer os atributos de forma mais flexível no encontro entre os sexos, na esfera doméstica, econômica e sexual?

A próxima categoria, “Divisão de tarefas" é resultado dos testemunhos sobre este questionamento, com os seguintes relatos femininos:

Sim, às vezes, quando eu peço, ou quando estou doente, daí ele faz alguma coisa; Ajuda um pouco, no cuidado com os filhos, mas deixa a desejar, tem que ficar pedindo; 


\section{"Seja homem": a narrativa, seja homem, e sua influência na subjetividade masculina}

Isso foi algo que pesou muito no meu casamento, porque eu não tinha nada de ajuda, eu tive uma figura machista dentro de casa e hoje é a última coisa que quero na vida;

Os homens apresentam sobre esta categoria, "Divisão de tarefas" relatos como:

Eu não gosto de fazer afazeres domésticos, evito ao máximo, faço esporadicamente, inclusive quando começou a ter muita louça em casa, comprei uma lava-louças; Minha mãe não trabalhava fora então eu enxergava que era obrigação dela cozinhar, limpar e estar tudo pronto para quando meu pai chegasse; Eu até vi, mas você não pediu, não sabia se era pra fazer.

É perceptível que ainda se conserva a obrigação das tarefas como papéis/atributos femininos, visto que ainda percebemos que alguns homens quando realizam uma tarefa, a colocam no campo da "ajuda" e não da divisão.

Em relação aos relatos apresentados nas entrevistas, Tagliamento \& Toneli (2010) apontam para problemática por trás desta realidade: consiste em atribuir a mulher o espaço doméstico, visão essa vivida e transmitida por gerações, o que acaba por naturalizar a casa como um espaço feminino, ou ainda, feminilizante, fazendo com que o homem se afaste desse lócus para não colocar em "risco" a sua masculinidade.

Se a divisão das responsabilidades domésticas e econômicas, acarretam tensões e impactos, a sexualidade não foge desta batalha. A categoria "Sexualidade", também emergiu durante a coleta de dados. Sobre este tema, foi possível perceber falas dos homens como:

Nunca tive orientação sexual em casa, muita coisa a gente escuta na rua, na escola, com os amigos; Minha mãe falava, olha filho você já pode engravidar qualquer mulher, então né; Então aquilo que eu aprendi foi com os amigos que eu andava na época que me tornei adolescente; Era um assunto falado de forma bem grosseira, não como orientação, meu pai falava de maneira esdrúxula - se for fazer faça bem feito, encape esse negócio; Com meu pai nunca, ele sempre foi muito fechado, minha mãe sempre foi 


\section{"Seja homem": a narrativa, seja homem, e sua influência na subjetividade masculina}

mais aberta e falava use camisinha, mas nunca discutimos abertamente; Em casa nunca tive orientação, a única orientação que eu tive era de que eu era homem e eu tinha que pegar mulher; Então às vezes a gente tá cansado, sou eu que tenho que tomar a iniciativa, que saco, sempre eu quero e daí quando a mulher quer? É uma situação de via dupla; Eu acho ótimo as mulheres tomarem iniciativa, acho muito certo, quebra aquela coisa do homem ter que começar, inclusive acho que tem muito homem que se sente intimidado quando a mulher faz isso e acaba até desistindo; Acho interessante quando mulheres tomam iniciativa, mas não gosto de mulheres atiradas, sabe, tem umas que perdem os limites, nesse ponto sou mais das antigas.

As falas das mulheres trazem, recortes como:

Tinha receio de falar com a minha mãe esse tipo de coisa e com o meu pai eu jamais falaria, porque meu pai sempre foi muito fechado; Homem não tomar a iniciativa, vejo como falta de interesse na parceira; minha mãe sempre foi mais próxima da gente, mas como a gente aprontava e teoricamente a gente era nova, essa parte sexual a gente não falava; Não, nunca tive orientação sexual em casa. muita coisa a gente escuta na rua com os amigos, na escola;

O tabu da sexualidade impede que o tema seja debatido entre as famílias. Não é um assunto para as reuniões familiares ou para o encontro entre pais e filhos. Infelizmente a educação sexual acaba sendo delegada para os espaços públicos, dentro da informalidade e com conceitos de senso comum. Assim, os fatos ligados à educação recebida em casa ou a ausência desta são as principais causas para que questões culturais venham a ser propagadas, onde, os homens são associados a virilidade, ao desejo sexual, a atividade na busca por sexo, implicando a mulher o papel oposto desta relação, papeis de subordinação ou até mesmo de desqualificação do desejo sexual feminino.

Atualmente esses argumentos estão sendo altamente questionados, pois muitas mulheres tem repensado sobre sua sexualidade, desejos e seu prazer. Debates como esse, ganham espaço e fortalecem esse movimento, oferecendo lugares para fala e reflexão sobre o tema. 


\section{"Seja homem": a narrativa, seja homem, e sua influência na subjetividade masculina}

Meler (como citado em Silva \& Macedo, 2012) afirma que a obrigação de tomar a iniciativa para o ato sexual implica um grau de exposição ao rechaço para o homem, o que pode ocasionar sofrimento nos mesmos. Além disso, eles também temem a iniciativa feminina, pois os angustia a perspectiva de não cumprir com o desempenho esperado. O temor está sustentado pelo estereótipo de que, quando solicitados sexualmente, é proibido negar, já que sua masculinidade será questionada.

A construção da subjetividade está atravessada pelos ordenamentos da sociedade, em relação as formas de se viver e para se estar inserido no mundo.

Burin (como citado em Silva \& Macedo, 2012) aduz que os homens utilizam os mecanismos de negação, supressão e projeção de alguns afetos considerados difíceis de manejar subjetivamente, tais como o medo, a dor e a tristeza, já que o homem deve manter-se corajoso, forte e insensível. Essas características, associadas à construção da identidade de gênero tradicional, são consideradas como a 'normalidade masculina', mesmo que sejam potencialmente patógenas para o psiquismo.

\section{Considerações finais}

O estudo nos permitiu verificar, que mesmo em 2020, ainda encontramos indícios do machismo estrutural, hoje também reconhecido como algo prejudicial ao próprio homem, que se constituiu pela masculinidade tóxica. Reconfirmar o quanto aspectos culturais e históricos impactam a subjetividade dos sujeitos, foi revelador e instigante.

Perceber a importância de estudos que busquem refletir sobre questões que potencialmente possam ser geradoras de sofrimento, conflitos, desconforto ou desequilíbrio às relações mostra também a urgência de buscarmos a ampliação da teoria sobre esta temática e a partir dela, poder pensar em ações que possam levar os sujeitos envolvidos neste cenário a perceberem, como ocorrem as construções do masculino e do feminino desde suas origens, e nas implicações e impactos que se inscrevem na subjetividade de cada um, no percurso de suas vidas e de suas relações. 


\section{"Seja homem": a narrativa, seja homem, e sua influência na subjetividade masculina}

Poder darvoz a esses atores, ouvir sobre o peso que a narrativa "seja homem" eos desdobramentos desta narrativa, colocou sobre cada um, possibilitou a reflexão sobre essa condição do ser homem em nossa cultura. Mesmo sendo um assunto que vem ganhando espaço e corpo nas discussões em diferentes áreas do conhecimento, percebe-se ainda que muitas vezes surge a partir de uma reivindicação feminina, que busca equidade.

Alguns estudos relatam o mal estar do masculino diante de sua constituição discursiva cultural. Mesmo reconhecendo que algo aconteceu, mas no sentido de flexibilizar os papéis de gênero, uma mudança sutil, através dos atributos que ampliam as possibilidades de ser e estar nas relações entre homens e mulheres.

Mas as tradições patriarcais ainda se fazem fortes e presentes e dão o tom nas relações de gênero. A narrativa "seja homem” ainda influencia a subjetividade masculina com forte carga desde a infância, influenciando a construção/desenvolvimento das representações de gênero. Existe vontade de mudança, um novo padrão de masculinidade emerge a cada conversa e a cada discussão, visto que muitos homens se sentem convocados a avaliar o que escutam sobre como poderiam ser, sentem-se impulsionados, mas ainda são conduzidos por crenças tradicionais.

Diante disso se torna imperativo o oferecimento de discussões em diferentes grupos, o quanto mais possíveis, que possibilitem uma reflexão e discussão sobre o impacto da constituição social das masculinidades na construção da subjetividade de cada ser humano

Evidenciar a questão dos mitos de origem e como as convicções afetam a subjetividade são temas de relevância, não só para o masculino, mas para seres humanos, que desejam, pensam e cujo inconsciente carregam questões muito além do que foi dito.

Como propagadores da cultura ou da representação social imposta, nos reconhecermos nesse papel em qualquer aspecto, por mínimo que seja nos faz refletir e repensar ações já feitas e dessa 


\section{"Seja homem": a narrativa, seja homem, e sua influência na subjetividade masculina}

maneira ajudar a propagar uma nova reflexão que futuramente pode se tornar em uma ação contínua proporcionadora de reinvenção.

Seja ao questionar uma piada sexista, ou ao fazer uma reflexão sobre algum dito popular enraizado, na criação dos filhos ao permitir a livre expressão dos seus sentimentos e não repetir respostas prontas do tipo "por que você é menina!" "porque você é menino!". Promover rodas de conversas para homens e mulheres com o intuito de gerar reflexões críticas em relação aos papéis que são desempenhados por eles, pois muitas vezes estas questões não são questionadas e sim só reproduzidas. O que nos leva a sugerir estudos futuros que se debrucem sobre os desdobramentos das falas, vivencias e emoções envolvidas na possível transformação desta realidade e busca por uma reinvenção deste modelo.

\section{Referências}

ALMEIDA, M. V. Gênero, masculinidade e poder: Revendo um caso do sul de Portugal. Anuário antropológico, Brasília, 20(1), 161-189, 1996

BARBOSA, M. J. S. Chorar, verbo transitivo. Cadernos Pagu, 0(11), 321-343.

Barbosa, S. A. P. Identidade de Gênero e Psicanálise: Reflexões [Monografia não publicada, Universidade Federal do Paraná]. Curitiba: Universidade Federal do Paraná., 2013. https:// doi.org/10.13140/RG.2.2.15567.38560

BARDIN, L. Análise de conteúdo. São Paulo: Edições 70, 2011

BASILIO, A. L. Homem não chora? Projeto com jovens visa o fim da masculinidade tóxica. São Paulo: Carta Capital, 2019.https://www.cartacapital.com.br/educacao/homemnao-chora-projeto-com-jovens-visa-o-fim-da-masculinidade-toxica/

BEAUVOIR, S. O Segundo Sexo II: A experiência vivida. São Paulo: Difusão Européia do Livro, 1967 


\section{"Seja homem": a narrativa, seja homem, e sua influência na subjetividade masculina}

BORIS, G. D. J. B. Falas masculinas ou ser homem em Fortaleza: Múltiplos recortes da construção da subjetividade masculina na contemporaneidade [Tese de Doutorado, Universidade Federal do Ceará]. Repositório Institucional UFC, 2000 .http:/ /www. repositorio.ufc.br/handle/riufc/35245

BOURDIEU, P. A Dominação Masculina. Educação \& Realidade,São Paulo, 20(2), 133-184, 1995.

BRAIT, B. Bakhtin: Conceitos-chave. Rio de Janeiro: Contexto, 2005

COELHO, V. P. O trabalho da mulher, relações familiares e qualidade de vida. Serviço Social e Sociedade, Porto Alegre, 23(71), 63-79, 2002.

CONNELL, R. W., MESSERSCHMIDT, J. W., \& FERNANDES, F. B. M. Masculinidade hegemônica: Repensando o conceito. Estudos Feministas, Florianópolis, 21(1), 241-282, 2013.

FLICK, U. Introdução à pesquisa qualitativa. Porto Alegre, Artmed, 2013..

FREUD, S. Edição standard brasileira das obras psicológicas completas de Sigmund Freud volume XIV: História do movimento psicanalítico, artigos sobre metapsicologia e outros trabalhos. (Ed., J. Strachey, Trad., Imago Editora, Vol. 14). Imago. (Trabalho original publicado em 1914).Rio de Janeiro, Imago, 2009.

FREUD, S. Edição Standard Brasileira das Obras Psicológicas Completas de Sigmund Freud Volume XVIII: Além do Princípio do Prazer, Psicologia de Grupo e outros Trabalhos. (Ed., J. Strachey, Trad., Imago Editora, Vol. 18). Imago. (Trabalho original publicado em 1921). Rio de Janeiro, Imago, 2009.

GABRIEL, M. R., \& DIAS, A. C. G. Percepções sobre a paternidade: Descrevendo a si mesmo e o próprio pai como pai. Estudos de Psicologia , Natal, 16, 253-261, 2011.

BUENO, B. O.; SOUSA, C. P. de; CATANI, D. B.; SOUZA, M. C. C. Docência, memória e gênero: estudos alternativos sobre a formação de professores . Psicologia USP, São 


\section{"Seja homem": a narrativa, seja homem, e sua influência na subjetividade masculina}

Paulo, [S. l.], v. 4, n. 1-2, p. 299-318, 1993. https://www.revistas.usp.br/psicousp/article/ view/34482. 1993.

MEMOH. Propósito https://memoh.com.br/\#proposito , 2020.

MOSELLO, S. C. M. Mulheres em múltiplas jornadas de trabalho e produção de subjetividade. Curitiba, Calligraphie, 2018.

NADER, M. B., \& CAMINOTI, J. M. Gênero e poder: A construção da masculinidade e o exercício do poder masculino na esfera doméstica. Anais do XVI Encontro Regional de História da Anpuh-Rio: Saberes e Práticas Cientificas. XVI Encontro Regional de História | ANPUH-Rio, Rio de Janeiro, 2014 http:/ / www.encontro2014.rj.anpuh.org/resources/anais/28/1400262820_ARQUIVO_ Generoepoderaconstrucaodamasculinidadeeoexerciciodopodermasculinonaesferadomestica. pdf

OLIVEIRA, A.S., OLIVEIRA, G.C. \& CARDOSO, J.S. Reflexos do machismo estrutural brasileiro em tempos de Covid 19: Quando o distanciamento social é tão letal quanto o vírus. Revista da Sessão Judiciária do Rio de Janeiro, v 24, 93-111., 2020. https://doi. org/10.30749/2177-8337.v24n49p93-111

RICHARDSON, R. J. Pesquisa social: Métodos e técnicas. São Paulo, Atlas, 1999 ROUDINESCO, E., \& PLON, M. Dicionário de psicanálise. São Paulo: Zahar, 1998 SCHREINER, G. A construção cultural dos papéis sociais: Adolescência, masculinidade e conflito com a lei. Consciência Social. São Paulo, 2008. http://www.conscienciasocial.net/ gallery/papeis $\% 20$ culturais_gabriela $\% 20$ schreiner.pdf

SCOTT, J. Gênero: Uma categoria útil de análise histórica. Educação \& Realidade, 20(2), 71-99. São Paulo, 1995 


\section{"Seja homem": a narrativa, seja homem, e sua influência na subjetividade masculina}

SILVA, F. C. F. DA, \& MACEDO, M. M. K. A escuta do masculino na clínica psicanalítica contemporânea: Singularidades de um padecer. Psicologia: Teoria e Pesquisa, Brasília, 28, 205-218. 2012

SILVA, S. G. DA. A crise da masculinidade: Uma crítica à identidade de gênero e à literatura masculinista . Psicologia: Ciência e Profissão, (on line) 26, 118-131, 2006. https://doi.org/10.1590/S1414-98932006000100011

TAGLIAMENTO, G., \& TONELI, M. J. F. (Não)trabalho e masculinidades produzidas em contextos familiares de camadas médias. Psicologia \& Sociedade, Recife, 22, 345-354, 2010. http://dx.doi.org/10.1590/S0102-71822010000200015

VIEIRA, M. M. F., \& ZOUAIN, D. M. Pesquisa qualitativa em administração: Teoria e prática. Rio de Janeiro: Editora FGV, 2005.

Submetido em 03 de março de 2021

Aceito em 15 de maio de 2021

Publicado em 8 de julho de 2021 